\title{
Jogo no Scratch como Objeto de Aprendizagem para a promoção da Alfabetização Científica e Tecnológica
}

Alexandre Simon*, Vanessa Lima Bertolazi Simon*, Elcio Schuhmacher ${ }^{\star *}$, Aldo Sena de Oliveira ${ }^{\star \star *}$

\section{Resumo}

Este artigo, analisa a contribuição do Objeto de Aprendizagem (OA) tipo jogo, desenvolvido no Scratch, como ferramenta pedagógica na promoção da Alfabetização Científica e Tecnológica (ACT) sob o tema Alimentação Saudável. O estudo foi realizado em uma turma do $2^{\circ}$ ano do ensino fundamental na CAIC Ayrton Senna da Silva de Balneário Camboriú. Para a análise da estratégia, foram utilizadas as categorias de Alfabetização Científica e Tecnológica: Prática, Cívica, Cultural e Lúdica. Os resultados mostraram que o jogo como objeto de aprendizagem, relacionado ao tema Alimentação Saudável, atende as prerrogativas das categorias de ACT, principalmente a Prática, Cívica e Lúdica e aborda de forma efetiva o tema proposto.

Palavras-chave: Scratch; Ciência e Tecnologia; Alimentação Saudável.

\section{Introdução}

O jogo está vinculado à aprendizagem e comunicação, sendo utilizado como ferramenta no desenvolvimento da capacidade psicomotora, própria da idade infantil. Através do jogo a criança aprende se divertindo, interage com seus pares e envolve-se com o processo educativo.

De acordo com Alves (2008) um dos primeiros trabalhos a basear-se na utilização dos meios eletrônicos para o desenvolvimento do raciocínio, foi o de Greenfield

\footnotetext{
* Mestre em Ensino de Ciências Naturais e Matemática - Universidade Regional de Blumenau (FURB). E-mail: asimon@furb.br; vlbsimon@furb.br

** Docente no Programa de Pós-Gradução em Ensino de Ciências Naturais e Matemática - Universidade Regional de Blumenau. E-mail: elcio@furb.br

*** Docente no Programa de Pós-Gradução em Ensino de Ciências Naturais e Matemática - Universidade Regional de Blumenau e Universidade Federal de Santa Catarina (UFSC) Campus Blumenau. E-mail: aldo.sena@ufsc.br
} 
(1988). Nesta obra, a autora destaca, que a medida em que as crianças se tornam produtoras do seu próprio conhecimento, tornam-se também consumidoras cada vez mais exigentes, "isso parece aplicar-se ao domínio dos computadores; o conhecimento de programação básica torna as crianças mais informadas sobre computadores e seus usos" (GREENFIELD, 1998, p. 144).

Neste sentido, Greenfield (1988, p. 143) destaca que "à medida que os computadores são introduzidos nos ambientes educacionais, torna-se cada vez mais aceito 0 fato de que as crianças irão aprender a programá-lo e também a usar o software”.

[...] precisamos permitir que nossos alunos nos indiquem o que gostam de fazer com a mediação da tecnologia, sejam as redes sociais como o Facebook, o WhatsApp, os jogos digitais, os aplicativos; enfim, as interfaces comunicacionais com as quais interagem. É fundamental indagar a estes sujeitos como se apropriam desses artefatos, o que fazem com eles, como compartilham e produzem conteúdos, evidenciando-os como protagonistas (ALVES, 2008, p. 4).

Nesse contexto, os Objetos de Aprendizagem trazem contribuições ao favorecerem experimentações e investigações e permitem mudanças de atitudes, valores e comportamentos pois permitem simular situações cotidianas dentro de um perfil pedagógico. Dessa forma, as mudanças possibilitadas pelos AO permitem trabalhar com aspectos da Alimentação Saudável de forma lúdica, como a que ocorre por meio de jogos de aprendizagem.

Para tanto, o presente artigo visa abordar o uso do jogo desenvolvido na plataforma Scratch, de código aberto, o qual está disponível para quaisquer fins e disponibilizada gratuitamente para programar jogos, animações e histórias interativas, as quais podem ser compartilhadas com outras pessoas. ilustrando um novo cenário nos espaços de aprendizagens. Partindo do pressuposto de que os alunos possam construir seu conhecimento a partir do uso das tecnologias digitais e utilizá-las na compreensão de conceitos acerca de uma alimentação saudável, através da Alfabetização Científica e Tecnológica.

\section{O jogo no Scratch como Objeto de Aprendizagem}

O jogo foi desenvolvido utilizando a plataforma Scratch, de código aberto, o qual está disponível para quaisquer fins e disponibilizada gratuitamente no site do Massachusetts Institute of Technology - MIT. O Scratch é um projeto do grupo Lifelong 
Kindergarten no Media Lab do MIT, sendo possível programar jogos, animações e histórias interativas, as quais podem ser compartilhadas com outras pessoas. $\mathrm{O}$ Scratch é uma plataforma, pensada para o desenvolvimento do pensamento criativo, e outras habilidades fundamentais na atualidade, como trabalhar de forma colaborativa, criativa e auxiliar no raciocínio

De acordo com o site oficial da plataforma, na última década, 35 milhões de crianças em mais de 150 países ao redor do mundo já usaram o Scratch para aprender o básico da codificação. Sua utilização perpassa o ambiente escolar, podendo ser utilizada em suas casas, bibliotecas, para uso de pais e educadores, com o intuito de promover a alfabetização em codificação, auxiliar no processo de aquisição de confiança com o uso de novas tecnologias, de modo interativo e divertido. O Scratch baseia-se na teoria do aprendizado construcionista desenvolvida por Seymour Papert, um dos membros fundadores do Media Lab

Prensky (2012, p. 27) reforça que, "aprender é um grande trabalho". Neste sentido, não há um método que funcione sozinho, ou seja, que a revolução da aprendizagem do século XXI, ocorra através da forma de aprender e na maioria das vezes, está centrada no aprendiz e pode ser divertida. $\mathrm{O}$ autor salienta que a barreira que delimita a aprendizagem da diversão e o trabalho, esteja desmoronando, e, portanto, uma nova geração de professores e aprendizes, passaram a utilizar a diversão como parte do processo de ensino.

De acordo com Prensky (2012), o sistema de ensino, que funcionou bem por séculos a fio, está entrando em colapso. A diferença mais importante talvez seja o fato de que as 'coisas' a serem aprendidas - informações, conceitos, relações e assim por diante - não podem mais ser simplesmente 'ditas' ou 'expostas' a essas pessoas.

Prensky (2012) ressalta que o fato de não estarmos tendo o êxito que gostaríamos na educação, poderia ser atribuído à utilização de métodos antigos, deixando de utilizar meios que poderiam ser mais eficientes. Devendo ser utilizadas ferramentas pedagógicas que promovam as descobertas, construções, interações e, acima de tudo, a diversão. Do mesmo modo, ao utilizar os recursos tecnológicos em sala de aula estamos ensinando e aprendendo ciência, através da resolução de problemas.

Ao pensarmos a questão das Tecnologias Digitais na sala de aula, imaginamos uma maneira de solucionar um problema presente, investigamos recursos dentro do programa (da linguagem de programação) e essa pesquisa tem potencial de gerar 
novas perguntas que nos levarão a mais pesquisas. Este é o movimento que existe em nosso cotidiano e é o viés que devemos apresentar dentro do ambiente escolar.

Alves (2008) reforça que a intenção não é transformar as escolas em lan houses, mas poderiam, ser um lugar diferenciado de aprendizagem através de jogos. Que viessem atender a questões éticas, políticas e culturais. Uma vez que o jogo é a primeira expressão da criança, e por conta disso a mais natural, desta forma, aproveitar para ensinar sob a ótica da espontaneidade do jogar da criança é tornar o ensino simples e de fácil entendimento.

Os jogos estão incorporados ao desenvolvimento humano de ensino e de aprendizagem, utilizados em diferentes fases da vida como ferramenta para aprender. Prensky (2012) destaca a utilização dos jogos digitais como recurso didático pedagógico e adianta que a precocidade na utilização desta ferramenta no âmbito escolar, traz benefícios no processo de ensino e aprendizagem.

Prensky (2012) considera que a aprendizagem baseada em jogos, será extremamente comum daqui há alguns anos, visto a facilidade no aprendizado e acessibilidade que os meios digitais, já oferecem. $\mathrm{O}$ autor ainda elenca três motivos que o fazem acreditar, que este processo ocorre e ocorrerá, com velocidade cada vez maior, estes motivos são:

1- atender as necessidades e às diferentes estilos de aprendizagem que compõe a atual e as futuras gerações;

2- é motivante e divertida;

3- é extremamente versátil, adaptando-se à maior parte das disciplinas, bem como aos conteúdos trabalhados em cada uma, favorecendo o aprendizado, desenvolvendo habilidades e sendo incrivelmente eficaz.

A escola por sua vez, deve utilizar as possibilidades, competências e habilidades dos alunos, valorizando seu contexto e suas experiências. De modo, a compreender que, a educação é um dos aspectos dos mecanismos formadores de cada indivíduo e faz parte do processo educativo de um sistema que constitui o eixo fundamental para o desenvolvimento do ser ao longo de sua vida em sociedade.

\section{Alfabetização Científica e Tecnológica:}

O pensamento científico e as novas tecnologias, são necessárias para resolver os problemas do século XXI. De acordo com Fourez (2005) a Alfabetização Científica e 
Tecnológica (ACT) está intimamente ligada a contextos sociais e culturais da sociedade. Do mesmo modo, a promoção da ACT visa oferecer aos alunos oportunidades para enfrentar as demandas da sociedade moderna, com vistas ao senso crítico e autonomia dos estudantes, tanto no âmbito escolar, quanto fora da instituição.

Nos primeiros anos de escolarização as crianças possuem muitas curiosidades e desejos de compreender o mundo em que vivem. Neste contexto, ao utilizar desta premissa, para abordar conteúdos de forma a envolver os alunos no ambiente científico. Cabe ao professor dos anos iniciais auxiliar no processo de desenvolvimento da criatividade, do espírito investigativo e da curiosidade de seus alunos, auxiliando-os no entendimento de conceitos presentes em seu cotidiano. Desse modo, a Alfabetização Científica e Tecnológica (ACT) nos anos iniciais do ensino fundamental contribui para a elaboração dos primeiros significados sobre o mundo.

Segundo Lorenzetti (2000), ciência e tecnologia precisam ser trabalhadas a partir das séries iniciais do ensino fundamental, partindo do princípio de que a preparação e o desenvolvimento deste indivíduo, se faça enquanto esteja sendo alfabetizado na língua materna.

Desta forma, é fundamental que a escola esteja preparada para o desenvolvimento desta habilidade, as quais farão parte da formação permanente desses indivíduos. Assim, a ACT assume um papel relevante na formação cidadã, contribuindo para que os alunos sejam inseridos na cultura científica, sendo mais críticos, adquirindo capacidade para discernir, julgar e fazer escolhas conscientes para uma melhor qualidade de vida (MARANDINO; SELLES; FERREIRA, 2009).

Este artigo baseou-se nas categorias de Alfabetização Científica e Tecnológica descritas inicialmente por Shen (1975) e ressificadas por Simon (2020), denominadas ACT-Prática, ACT-Cívica, ACT-Cultural e ACT-Lúdica. A seguir são descritas cada uma das categorias, consideramos o uso do termo Alfabetização Científica e Tecnológica ao longo da pesquisa e na categorização, assumindo o fato do conhecimento científico e tecnológico contemplar as prerrogativas atuais e as demandas contemporâneas.

\section{Alfabetização Científica e Tecnológica Prática (ACT-Prática)}

Refere-se à criança ter as informações e a posse do conhecimento científico, no intuito de resolver problemas práticos voltados às necessidades básicas humanas, 
como: saúde, alimentação e habitação. De acordo com Shen (1975, p. 46, tradução nossa) “o conhecimento científico está longe de ser a resposta completa, mas oferece um antídoto parcial".

A ACT-Prática "deve ser ensinada nas escolas, independente da criança saber ler e escrever" (LORENZETTI, 2000, p. 50) e auxiliar na apropriação do código escrito. De acordo com Simon (2020) esta categoria fundamenta-se na compreensão de conhecimentos científicos, de fenômenos naturais, dos processos e funcionamento dos aparatos tecnológicos do cotidiano.

\section{Alfabetização Científica e Tecnológica Cívica (ACT-Cívica)}

A ACT-Cívica trata em expor à ciência a público, no âmbito de desenvolver o senso crítico comum, proporcionando que todos possam ter acesso às informações científicas, e até mais que isso, na tomada de decisões.

Shen (1975) destaca que o cidadão comum muitas vezes não se preocupa em pensar muito sobre as questões mais técnicas (saúde, energia, recursos naturais, ambiente, alimentos e agricultura, segurança dos produtos, espaço exterior, comunicação, transporte, etc.) ou em tentar formar opiniões consideradas de senso comum sobre elas. Sugerindo que assuntos desta ordem, fique a cargo de especialistas. Permite que a criança se torne mais consciente das questões científicas, de modo a participar de forma ativa de uma sociedade cada vez mais científica e tecnológica. É dispor a ciência em sua totalidade, democratizando o saber científico à toda população (SIMON, 2020).

\section{Alfabetização Científica e Tecnológica Cultural (ACT-Cultural)}

ACT-Cultural é motivada pelo desejo das crianças em conhecer algo sobre a ciência, sua constante evolução e seus desdobramentos, unindo a cultura científica à cultura humana. Segundo Simon (2020), o aluno pode buscar conhecer mais sobre a ciência em revistas e jornais, buscando significados para os acontecimentos ao seu redor. Do mesmo modo, Lorenzetti (2000, p. 51-52) destaca que "jornais e revistas também informam constantemente a evolução da ciência. [...] que estes meios de comunicação possam circular livremente pelas escolas", permitindo o acesso das crianças a estas informações. 
De acordo com Shen (1975) a ACT-Cultural pode exercer um efeito prático sobre o que tem sido chamado de nova pseudociência, relacionados à crenças supersticiosas e ocultas, que vão da astrologia ao modismo alimentar, até o catastrofismo cósmico, utilizando como antídoto eficaz um pouco de conhecimento científico.

\section{Alfabetização Científica e Tecnológica Lúdica (ACT-Lúdica)}

Esta categoria pode ser definida como a facilidade da criança associar os conceitos científicos e tecnológicos, às atividades comuns executadas em seu cotidiano. De acordo com Simon (2020) as atividades lúdicas estão presentes na cultura e no desenvolvimento humano, fazendo parte do contexto individual ou coletivo, contribuindo para o desenvolvimento motor, cognitivo, afetivo e nas relações sociais.

De acordo com Leontiev (1998) na atividade principal da criança o lúdico não está presente somente no desenvolvimento de jogos, brincadeiras e teatrinhos, mas está intrínseco ao desenvolvimento infantil, por ser por meio da ludicidade sua forma de aprender, socializar e descobrir e fazer parte do mundo real.

\section{Metodologia Empregada}

Este trabalho foi desenvolvido seguindo os princípios da pesquisa qualitativa de Bogdan e Biklen (1991), a qual constará de um estudo de caso de observação participante, contemplando a observação para coleta de dados, centrando na escola como ambiente a ser investigado.

Inicialmente foi realizada uma pesquisa bibliográfica buscando fundamentação teórica para o tema abordado. A partir desta pesquisa, o jogo foi elaborado, considerando o tema Alimentação Saudável, respeitando idade/série dos alunos. Bogdan e Biklen (1991) destacam sobre a preocupação com o ambiente a ser escolhido, pois em virtude da técnica utilizada é importante que haja a isenção do pesquisador na coleta e análise dos dados. Para o registro dos dados foram utilizados os seguintes instrumentos: fotos, vídeos, registros elaborados pelos estudantes e diário de campo.

\section{Aplicação da estratégia}

O tema foi abordado, levando em conta que muitos pais, em virtude do mais prático, inserem alimentos ao cotidiano da criança que não possuem valor nutricio- 
nal, pelo contrário, muitos são calóricos e pobres em vitaminas e sais minerais. De acordo com os dados da Pesquisa Nacional de Saúde do Escolar - PeNSE, realizada em 2015, a alimentação do educando está longe de ser a mais saudável.

De acordo com a Coordenadora de Alimentação e Nutrição do Ministério da Saúde, Michele Lessa, uma alimentação saudável evita que ao longo dos anos as crianças e adolescentes desenvolvam problemas que irão atrapalhar a qualidade de vida deles. Por isso, é fundamental que os pais insiram alimentos in natura ou minimamente processados na lancheira das crianças, para que elas possam ter um futuro com mais saúde. Para tanto é necessária uma mudança de hábitos tanto do próprio aluno como também da família, para que qualquer abordagem realizada na escola se torne efetiva (MACIEL, 2019).

A pesquisa foi realizada com 28 alunos do $2^{\circ}$ Ano do Ensino Fundamental na escola pública CAIC Ayrton Senna da Silva no município de Balneário Camboriú em Santa Catarina. Primeiramente, a turma do $2^{\circ}$ Ano do Ensino Fundamental, participou de uma aula (45 minutos) no Laboratório de Ciências, onde foi explanado sobre a importância de uma alimentação saudável, com a participação direta dos educandos. A fim de promover a ACT, foi utilizada linguagem científica sobre o tema proposto, com a finalidade de indicar os atributos de vitaminas, nutrientes e sais minerais contidos nos alimentos, bem como, indicar os malefícios do excesso de gorduras e açúcares. Nesta perspectiva, buscamos indicar, que a melhor alimentação é aquela em que todos os grupos alimentares estejam presentes, de forma equilibrada e que o doce pode aparecer de vez em quando em suas dietas.

No segundo momento, os alunos foram dirigidos até o laboratório de informática, onde o jogo do Scratch, já estava disponível nos computadores, sendo destinado a este espaço mais aula (45 minutos). Inicialmente foi retomado o assunto visto no Laboratório de Ciências e posteriormente explicado como o jogo funciona, indicando o uso das setas do teclado para a movimentação do cesto e como é feito para retornar ao jogo, em caso do cesto encostar no donuts rosa. Atividades desta natureza, que envolvam o ensino de Ciências e a utilização de jogos ou artefatos tecnológicos, fazem parte do contexto desta unidade escolar, à luz de metodologias e práticas que envolvam os alunos aos temas propostos pelos professores regentes e as demandas da sociedade contemporânea. 


\section{Desenvolvimento do jogo}

Neste ensaio utilizamos a plataforma Scratch (Figura 1), para o desenvolvimento de um jogo que atendesse a idade / série dos alunos, bem como, estar de acordo com o tema proposto pela ACT, Alimentação Saudável.

A interface do Scratch possui três áreas principais: armazém de comandos, área de edição de recursos e área de estágios. No armazém de comandos são encontradas estruturas pré-programadas, as quais estão dispostas em blocos que determinam as funções a serem executadas no projeto, são separados por funções e recebem uma cor para melhor identificá-los, ao escolher entre suas funções e quando estiverem no projeto, para selecionar é preciso clicar no bloco da ação que desejar e arrastar até a área de edição.

$\mathrm{Na}$ área de edição, é possível combinar os blocos para executar uma dada função, a soma destes blocos forma a linha de comando do programa, a qual atribui instruções para os personagens (atores), movimentos (quantidade e fantasias), sons etc. de acordo com objetivo do projeto. A área de estágios apresenta o cenário de simulação e os atores, é nesta parte que acontecem as funções programadas. Os projetos realizados ficam disponíveis para a comunidade de forma interativa e colaborativa, esta plataforma online pode ser compartilhada através de links de acesso.

Deste modo, ao desenvolvermos o jogo, abordamos o assunto através das frutas que devem ser coletadas com o cesto coletor e seu movimento dentro do jogo ocorre, através das setas do teclado. A medida que o aluno consegue pegar as frutas, um contador mostra a quantidade coletada. Para demonstrar que o doce pode ser prejudicial, quando consumido fora de hora, após a coleta de 13 frutas aparece um donuts rosa, o qual se pego pelo cesto o jogo acaba (Não era o momento do doce). Durante o jogo aparece um donuts amarelo, este pode ser pego, pois exemplifica o fato de que as vezes pode-se comer doce, por isso no jogo aparece esporadicamente. 
Figura 1: https://scratch.mit.edu/projects/383480026/

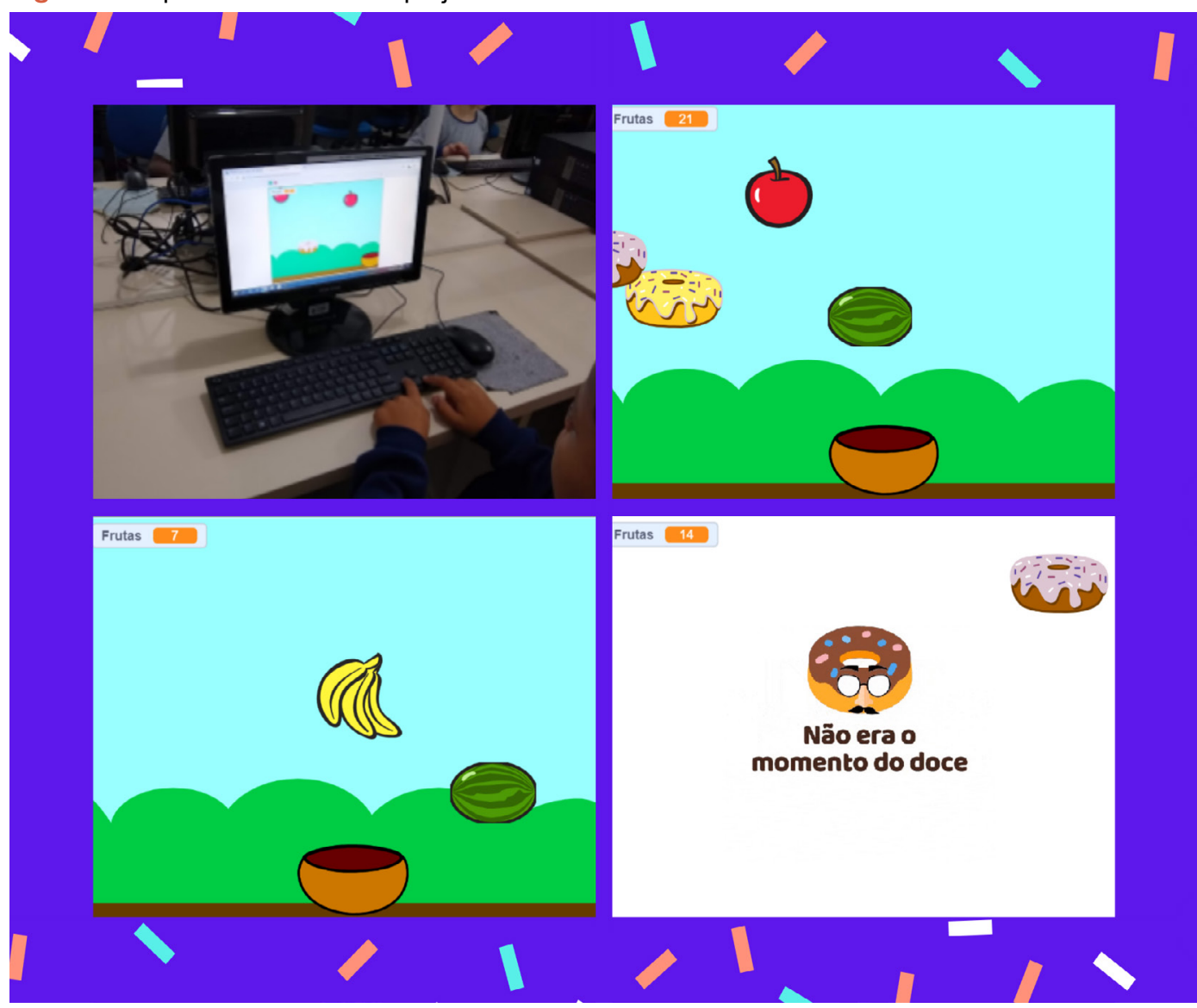

Resultados e Discussão

O caráter interdependente e global de problemas da sociedade contemporânea clama iniciativas inovadoras para encontrar formas que permitam aos alunos compreender os problemas do seu cotidiano de forma mais ampla, não apenas como vida comum, mas suas transformações sociais, pessoais, éticas e culturais.

Deste modo, ao utilizar jogos desenvolvidos no Scratch como objeto de aprendizagem e promoção da ACT, traduz uma nova tendência no ensinar, pois utiliza uma abordagem lúdica, que denota um tema tão importante como a Alimentação Saudável. 
Em consonância com as prerrogativas da sociedade contemporânea, a Alfabetização Científica e Tecnológica, um dos temas desta pesquisa, corrobora com a proposta de popularização e difusão da ciência logo no ensino fundamental, com claro interesse em despertar o interesse por jogos didáticos acessíveis e instrutivos.

Ao utilizarmos o jogo como estratégia pedagógica sobre o tema Alimentação Saudável, observou-se o alcance individual e coletivo nesta proposta, pois durante a estratégia os alunos conversavam acerca da quantidade de frutas coletadas e principalmente indicavam uns aos outros sobre quantos donuts amarelos eram pegos. Deste modo, ao retomarmos o assunto da aula do Laboratório de Ciências, logo os alunos associavam a quantidade de frutas estar presente em maior quantidade em suas dietas, bem como o fato do doce poder ser consumido de vez em quando.

Como parte desta pesquisa, buscamos analisar a estratégia do uso do jogo sobre alimentação saudável, frente às categorias de ACT, como pode ser observado na Figura 2.

Figura 2: Análise do jogo frente as categorias de ACT

\section{Categorias de Alfabetização Científica e Tecnológica}

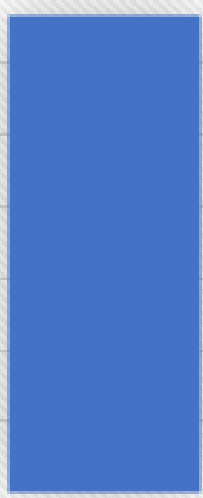

ACT-Cívica

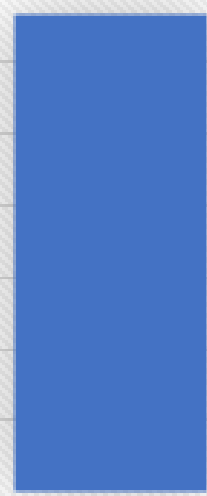

ACT-Prática

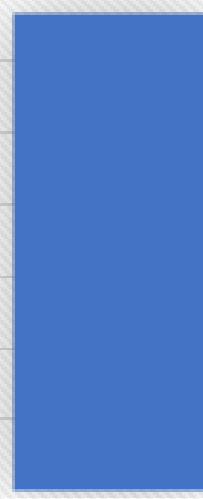

ACT-Lúdica
ACT-Cultural

Fonte: Autor

Deste modo, identificamos a Alfabetização Científica e Tecnológica Prática (ACT-Prática), quando o jogo aborda sobre a alimentação saudável e os alunos con- 
seguem identificar que o doce pode ser consumido de vez em quando, visto que o mesmo, é representado pelo donuts amarelo e que o melhor é o consumo de frutas e verduras em suas refeições. Identificamos a Alfabetização Científica e Tecnológica Cívica (ACT-Cívica) pelo jogo abordar de forma efetiva na tomada de decisão, ao demonstrar que uma alimentação saudável deve estar presente no seu cotidiano e contemplar frutas e verduras. Ou seja, o jogo auxilia ao demonstrar que o doce possui momento certo para ser consumido, e que, ao pegá-lo em momento incorreto não será bom para sua saúde.

Levando-se em consideração que as vivências e as experiências das crianças são fundamentais em seu aprendizado. Em algum momento de suas vidas, seus pais ou professores, lhes falaram sobre os alimentos saudáveis, o jogo por sua vez, leva-os a retomar este contexto e lhes dá uma nova ressignificação, haja visto, que estamos utilizando um objeto de aprendizagem que não está presente em seu contexto escolar ou familiar, sendo possível o aluno fazer a associação do mesmo a uma situação do dia a dia, por esta razão podemos dizer que a atividade contempla a Alfabetização Científica e Tecnológica Lúdica (ACT-Lúdica). Nesta perspectiva do ensino fundamental assume-se o fato de levar ao aluno, todo e qualquer conhecimento, à luz da interação, brincadeiras e ludicidade. Não foi identificado a Alfabetização Científica e Tecnológica Cultural (ACT-Cultural) no jogo.

Alves (2008), acrescenta que os jogos podem ser articulados, a fim de serem pedagógicos e divertidos, sendo necessário um diálogo entre professores e desenvolvedores, para que juntos contemplem as novas perspectivas na área de desenvolvimento de jogos eletrônicos e digitais para o ambiente pedagógico.

Deste modo, é importante ressaltar que o conhecimento científico, sob a ótica da ACT, vai além do escrever ou ler os códigos alfabéticos, e constitui-se como um meio de entender a ciência como um elemento da cultura humana, de compreensão do mundo e dos fenômenos naturais envolvidos. À medida que é oportunizado aos alunos um acesso sobre a ciência e a tecnologia, ocorre maior familiarização com este contexto, sendo maior a possibilidade de difusão da ACT no âmbito escolar e social, desenvolvendo o senso crítico, raciocínio lógico e sua capacidade de atuação nas tomadas de decisões. 


\section{Considerações Finais}

Deste modo, o desenvolvimento de habilidades voltadas a ciência e tecnologia, pautadas com a vida cotidiana, se fazem necessários na escola, a fim de alcançar um ensino que permita a tomada de decisão em democracias participativas. Seguindo esta linha de pensamento, destaca-se o ambiente escolar como propulsor de uma sociedade, a qual esteja voltada a desenvolver o conhecimento de forma ampla e abrangente, condizente com as prerrogativas do século XXI.

Justificando que a utilização de jogos com temas de cunho científico, podem direcionar os conhecimentos para finalidades de ACT práticas, cívicas, culturais e lúdicas, favorecendo um ensino contextualizado e interdisciplinar. Com efeito, ao processo de ensino, tornar-se-á divergente ao modelo tradicional, ao enfatizar o desenvolvimento crítico, criativo e argumentativo dos alunos.

Ao utilizarmos o jogo, como meio para dialogar um tema que requer atenção do aluno, da família e da escola, como a Alimentação Saudável, é importante fazer uso de ferramentas pedagógicas que estejam acessíveis aos alunos e principalmente que envolvem os pressupostos da Alfabetização Científica e Tecnológica, em voga no âmbito escolar. Deste modo, unir o que os alunos gostam, que é jogar, aos seus conteúdos escolares favorece um ensino e aprendizagem efetiva de forma divertida e lúdica.

\section{Scratch Game as a Learning Object for the Promotion of Scientific and Technological Literacy}

\section{Abstract}

This article analyzes the contribution of the game-like Learning Object (LO), developed in Scratch, as a pedagogical tool in the promotion of Scientific and Technological Literacy (ACT) under the theme of Healthy Eating. The study was carried out in a class of the 2nd year of elementary school at CAIC Ayrton Senna da Silva in Balneário Camboriú. For the analysis of the strategy, the categories of Scientific and Technological Literacy were used: Practice, Civic, Cultural and Playful. The results showed that the game as a learning object, related to the Healthy Eating theme, meets the prerogatives of the ACT categories, mainly Practice, Civic and Playful, and effectively addresses the proposed theme.

Keywords: Scratch; Science and technology; Healthy eating. 
ALVES, Lynn. Relações entre os jogos digitais e aprendizagem: delineando percurso. Educação, Formação \& Tecnologias; v. 1(2), p. 3-10, 2008.

BOGDAN, Robert.; BIKLEN, Sari. Investigação qualitativa em Educação: Uma introdução à teoria e aos métodos. Portugal: Porto Editora, 1991.

FOUREZ, Gerard. Alfabetización científica y tecnológica: acerca de las finalidades de la enseñanza de las ciencias. $1^{\underline{a}}$ ed. $3^{\underline{a}}$ reimp. Buenos Aires: Colihue, 2005.

GREENFIELD, Patricia Marks. O desenvolvimentos do raciocínio na era da eletrônica: os efeitos da TV, computadores e videogames. Tradução Cecilia Bonamine. São Paulo: Summus, 1988.

LEONTIEV, Alexei Nikolaevich. Uma contribuição à Teoria do Desenvolvimento da Psique Infantil. In: Vigotski, Lev. Semenovich. Linguagem, desenvolvimento e aprendizagem. Trad. Maria da Penha Villalobos. São Paulo: Ícone, 1988.

LORENZETTI, Leonir. Alfabetização científica nas séries iniciais. Florianópolis, UFSC, 2000. Dissertação, Mestrado em Educação - Centro de Ciências da Educação, Universidade Federal de Santa Catarina, 2000.

MACIEl, Victor. Saiba como a criança pode ter uma alimentação saudável na escola. Disponível em: https://antigo.saude.gov.br/noticias/agencia-saude/45242-saiba-como-a-crianca-pode-ter-alimentacao-saudavel-na-escola. Acesso em: 13 de fev.de 2021.

MARANDINO, Martha; SELLES, Sandra Escovedo; FERREIRA, Marcia Serra. Ensino de biologia: histórias e práticas em diferentes espaços educativos. São Paulo: Cortez, 2009.

PRENSKY, Marc. Aprendizagem baseada em jogos digitais. São Paulo: Editora Senac São Paulo, 2012.

SHEN, Benjamin. Science Literacy and the Public Understanding of Science. Communication of Scientific Information. Karger, Basel. 44-52, 1975. Disponível em: https:/www.karger.com/Article/ Abstract/398072, Acesso em: 20 de fev. 2021.

SIMON, Vanessa Lima Bertolazi. A alfabetização científica e tecnológica por meio de atividades práticas: olhares para os campos de experiência na pré-escola. Blumenau, FURB, 2020. Dissertação, Universidade Regional de Blumenau, Mestrado em Ensino de Ciências Naturais e Matemática - Programa de Pós-Graduação em Ensino de Ciências Naturais e Matemática, 2020. Disponível em: http://www.bc.furb.br/docs/DS/2020/366809_1_1.PDF. Acesso em: 21 abr. 2021. 